\title{
Herpes encephalitis
}

\section{The clinical picture}

\author{
A. M. G. CAMPBell \\ Bristol United Hospitals
}

\begin{abstract}
Summary
The three forms of herpetic encephalitis have been outlined and particular stress has been laid on herpes simplex encephalitis, which accounts for a large percentage of cases showing necrotizing encephalitis.

The possible application of antiviral drugs such as idoxuridine in the treatment of this disease has been mentioned.
\end{abstract}

A case of herpes B encephalitis contracted from a monkey bite has been described, and care in the handling of monkeys has been stressed.

\section{Herpes simplex encephalitis}

The importance of herpes simplex virus infection as a cause of acute necrotizing encephalitis has become increasingly recognized due to better methods of diagnosis, isolation of the virus, fluorescent antibody techniques, viral antibody studies and the presence of typical intranuclear inclusion bodies. It is probable that the majority of cases of necrotizing encephalitis are due to herpes simplex, although recently Heathfield et al. (1967) have shown a very similar type of encephalitis as a result of Coxsackie infection, and possibly psittacosis can also produce this type of necrotizing encephalitis. It was in 1941 that herpes simplex was first isolated from a fatal case of encephalitic illness (Smith, Lennette \& Reames, 1941), and it was realized that what usually, in the skin and eye, is a benign infection can produce this fatal outcome. About a hundred cases have been proved since that date.

The introduction of possible antiviral therapy in this herpetic group of viruses has emphasized the importance of early diagnosis in a disease in which previously diagnosis had been somewhat academic. The predilection of this particular virus for either one or both temporal lobes of the brain leads to confusion with a space-occupying lesion and many cases are sent to neurosurgical units.

In Table 1 the age incidence of twenty cases, described by Miller, Hessor \& Tompkins (1966), is shown. The incidence in adults is interesting. It may
TABLE 1. Herpes simplex (after Miller et al., 1966): twenty cases (age and season)

\begin{tabular}{lcccccc}
\hline Age & $0-10$ & $11-20$ & $21-30$ & $31-40$ & $41-50$ & $51-60$ \\
\multicolumn{7}{c}{} \\
Remaining & 2 & 0 & 4 & 1 & 2 & 8 \\
Month & Jan & Feb & March & April & May & June \\
& 3 & 1 & 1 & 0 & 0 & 1 \\
& July & Aug & Sept & Oct & Nov & Dec \\
& 3 & 5 & 1 & 2 & 2 & 1 \\
Total & 20 & & & & & \\
\hline
\end{tabular}

indicate that these adults fail to acquire immunityo from this common disease in their childhood. It is possible that this is a primary infection with herpes, as serum antibodies rise in the serum and are not present initially. However, encephalitis usually occurs over the age of 5 years, whereas herpes infection is known to affect young children. Rawls $e t$ al. (1966) have considered it to be due to re-activation of a latent infection and sometimes cases give a history of recurrent herpes labialis, which would support this view. Miller \& Ross (1968) have recently suggested the prognosis is markedly worse in an adult both for mortality and morbidity, and it was only in cases under 15 years that the prognosis was to any degree favourable in their recent series.

The seasonal incidence, if anything, suggests that it occurs more commonly in the summer. As cases are often sporadic it is more difficult to diagnose than other infectious causes of encephalitis such as measles, rubella, mumps, chickenpox or influenzal and Coxsackie infections, and one gets little help from environmental circumstances in the diagnosis.

In Bristol in the last $\mathbf{1 0}$ years there have been ten cases of proved herpes simplex encephalitis and all have died. Four of these cases have been admitted direct to neurosurgical units as cases of probable space-occupying disease.

It is a matter of conjecture as to whether infection of the brain with this virus can be precipitated by other external factors, as one case is recorded coming on after a highly malignant sarcoma had been 
treated with radiotherapy, and it was suggested that the radiotherapy for the malignancy had depressed the immune reaction. Another case described by MacCallum, Potter \& Edwards (1964) followed a head injury after a fall from a horse and this child, aged 11 years, was at first thought to be a case of subdural haematoma: the correct diagnosis was made by finding the virus in a brain biopsy.

Diagnosis is not always easy because the patients may start with a non-specific general reaction such as sore throat, headache, stomatitis and diarrhoea, and this prodromal phase may last for from 2 to 14 days. It is true of many virus diseases that this generalized onset is followed by infection of the nervous system by a neurological or haematogenous route, but it is of great interest and importance that the maximum effect in herpes encephalitis appears to be on the temporal lobes, and memory defects, psychosis and personality changes are early symptoms. Hemianopia can also be an early symptom and in Table 2 are

TABLE 2. Signs

\begin{aligned} & \hline 1. Aphasia \\ & 2. Epilepsy or myoclonic twitching \\ & 3. Hallucinations \\ & 4. Hemianopia \\ & 5. Focal paralysis \\ & 6. Abnormal motor activity \\ & 7. Abnormal behaviour \\ & 8. Coma \\ & 9. Sometimes herpetic stomatitis \\ & 10. Myalgia \\ & \hline\end{aligned}

outlined the common presenting symptoms and signs. The differential diagnosis is considered in Table 3 and one most important problem is differentiating between herpes encephalitis and a space-

TABLE 3. Differential diagnosis

Cerebral abscess

Cerebral tumour

Tuberculous meningitis (sometimes low sugar in CSF)

Subdural haematoma (after injury)

Other forms of meningitis

Cerebro-vascular disease occupying lesion of the brain, such as an abscess or tumour. It is made much more difficult by the fact that often there is unilateral oedema and swelling of the temporal lobe and displacement in the arteriogram and air picture. Lumbar puncture may help as it usually shows a rise in cells and protein and blood is often present. Sometimes the cerebrospinal fluid sugar content is reduced, but it is never as consistently low as in tuberculous meningitis, although it has been known to cause confusion. In this connection it is well to remember that certain tumours, notably microgliomatoses, may also show misleading figures, both in connection with CSF cell content and low sugar reading, as also may the fungal disease, torulosis. If the CSF is found to contain cells and the EEG to show a slow focal activity in the temporal lobe, the next measure is a carotid arteriogram and if this in turn should show vessel displacement, then biopsy becomes essential. It is usually by a biopsy of the brain that the virus is identified and the finding of intranuclear bodies will suggest the diagnosis of herpes simplex encephalitis. The recent introduction of fluorescent antibody technique has also improved the accuracy of diagnosis in life. It has become increasingly important to make this diagnosis as early as possible in view of the treatment of cases with idoxuridine. The essential steps in the diagnosis are outlined in Table 4

A typical case history of one of the Bristol cases is as follows:

Mrs C.H., aged 57 years, was admitted to hospital with a history of headache and vomiting for 10 days and a pyrexia of about $100-102^{\circ} \mathrm{F}$. She was thought to be suffering from influenza but was found to have neck stiffness, to be markedly confused and had a left hemiparesis and a left hemianopia. A lumbar puncture showed twenty cells, mainly lymphocytes, and a normal sugar of $60 \mathrm{mg} / 100 \mathrm{ml}$. She was referred to a neurosurgical unit, where an arteriogram showed swelling of the right side of the brain and a slight shift to the left, while an EEG showed high amplitude slow delta discharges in the right frontal region. Needle biopsy was done three days after admission

TABLE 4. Essentials of diagnosis

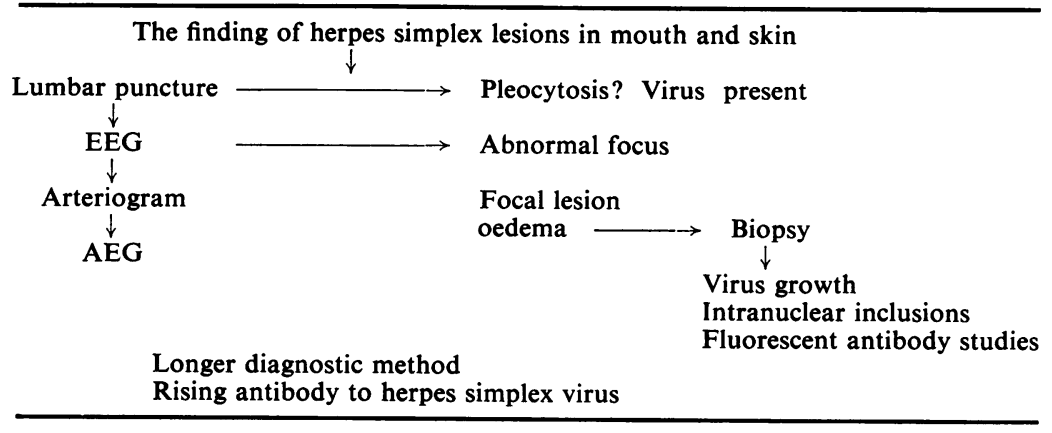


to the neurosurgical unit and necrotic material was removed from the temporal lobe. She died 7 days after admission.

From the biopsy and necropsy material herpes virus was grown and intranuclear inclusion bodies were found at post-mortem. It is interesting that only from the temporal lobe (from the biopsy and necropsy material) was herpesvirus grown, while none was grown from other parts of the brain or from the faeces. The neurosurgeon was struck by the extreme necrosis of brain which in his biopsy resembled pus, although it was clear on examination of the biopsy material that the condition was due to an encephalitis.

The introduction of anti-viral agents, such as idoxuridine, which has been proved to be of value in the treatment of the skin and eye lesion of herpes simplex, has already led at least three observers to try either intra-arterial or intravenous administration of this agent in cases of herpes encephalitis. In the case reported by MacCallum et al. (1964), the intraarterial route was used because it was thought that the drug did not easily pass the blood-brain barrier and the administration was by arterial perfusion via the carotid artery in doses of $100 \mathrm{mg}$ over $2 \mathrm{hr}$ on the 1st day and then reducing the dose to $200 \mathrm{mg} /$ day over the succeeding days with a total dosage of $14 \mathrm{mg} / \mathrm{kg}$ body weight. In this case full recovery was not obtained and the patient remained quadriplegic, confused and dysphasic.

Recently a more optimistic report has come from Marshall (1967) in Glasgow. In this case intravenous Ringer lactate, containing $0.75 \mathrm{~g}$ idoxuridine/ $500 \mathrm{ml}$, was given, at a rate of $3 \mathrm{~g}$ in $24 \mathrm{hr}$ with a total of $7.5 \mathrm{~g}$ over $2 \frac{1}{2}$ days. In their patient, who had not been improving, there was a fall in the patient's white count from 4000 to 1900 (but a rapid rise after the therapy was stopped), and it was noticed that consciousness immediately improved, as did the power in the left arm, and apart from some apraxia the patient rapidly improved and 2 months later had more or less recovered completely.

Other cases have been recorded by Evans et al. (1967) with no recovery, but therapy was begun late in the disease, $48 \mathrm{hr}$ after the onset. Breeden, Hall \& Tyler (1966) record a case in which recovery was also relatively complete. It must be admitted that some of these cases were accompanied by decompression and this has been a factor in the recovery, but it also seems possible that if therapy with idoxuridine can be commenced early in the disease it may have som: beneficial effect and, despite the fact that it is toxic and can produce leucopenia and liver damage, it seems worthy of trial in a disease which is so uniformly fatal if left untreated. Only time and more usage will help us to estimate how valuable it is in treatment and it is, of course, possible that more anti-viral drugs will be discovered so that the diagnosis, originally only of academic value, has now become of much more practical importance. There always will be difficulties in getting an adequate concentration of the drug through the blood-brain barrier without damaging the patient and particularly adversely affecting his white blood count. At least, however, we have some hopes now of treating a viral disease of the nervous system.

A word should be said about the use of steroids. It is possible that steroids may improve, at least temporarily, cases of herpes encephalitis but, like decompression, their value is difficult to assess, and if all forms of treatment are used on the same case it will remain difficult to evaluate which has been the most successful.

\section{Herpes B encephalitis}

There exists a virus very closely allied to herpes simplex, herpes B, which occurs naturally in monkeys and recently has become important as a result of several scientific workers becoming infected after a monkey bite, the virus being present in the saliva of the monkey. This virus has been isolated from the nervous system of laboratory workers who have died of encephalitis following a monkey bite. It appears that the human being is more likely to develop encephalitis than is the monkey. This virus also produces intranuclear inclusion bodies similar to herpes simplex.

We were unlucky enough in Bristol to have a probable case of this disease which proved fatal and it is worth recording this in more detail. In June 1963 a university professor, a man of 47 years, with a distinguished record on work concerning monkey behaviour and animal territory, in attempting to catch an escaped monkey was bitten on the hand. It should be emphasized that this professor had normally taken few precautions in handling his monkeys as he had become on very friendly terms with the animals.

A fortnight after the bite his wife began to notice personality changes, his memory became poor and he showed symptoms of confusion, difficulty in sleeping and excessive emotional reaction. About 4 weeks after the bite he indicated he was feeling very ill and complained of headache and 5 weeks after the bite he was admitted as an emergency to the Bristol Royal Infirmary in a comatose state and obviously gravely ill, with a left hemiplegia and left hemianopia. Differential diagnosis considered was between acute encephalitis and a space-occupying lesion on the right side of the brain. Angiography and cerebral biopsy proved that the condition was an acute encephalitis. Blood culture was negative but the cerebrospinal fluid showed 1240 white cells and contained pus, the protein was $225 \mathrm{mg} / 100 \mathrm{~m}$, 
cultures were sterile, glucose was normal and the Lange curve was negative. A fortnight after admission this patient died. Blood examination was negative to herpes simplex antibody and although herpes B was not grown from this man's brain, Dr Beale of Glaxo Laboratories reported a rise in titre to virus $B$ and also considered that the monkey which bit the professor had evidence of virus B infection. Dr Beale thought that in view of the history and the rise in titre this unfortunate man had died as a result of being bitten by his monkey. As a result of this tragedy all the monkeys concerned with this professor's department were sacrificed and killed and far-reaching alterations were made in the handling of monkeys experimentally, both in Bristol University and other universities in the country.

This viral disease of monkeys is more common in monkeys from the Far East than African monkeys, and the monkey concerned in this case was an African monkey, but further investigations proved that it had mixed intimately with monkeys which had come from India and it had probably acquired infection from them. In any person showing a history of an encephalitic-like illness, following a monkey bite, this disease should immediately be considered.

\section{Zoster and varicella}

Finally one should mention herpes zoster and chickenpox, which both can produce encephalitis, although rarely. In the case of herpes zoster the encephalitic cases are usually accompanied by herpes involving the fifth cranial nerves and very often those cases produce the Ramsey-Hunt syndrome. What is particularly striking, however, is the benign nature of the illness and in no case seen by the author has a fatal outcome occurred. The most severe case was that of a 60-year-old woman with marked pleocystosis and a typical Ramsey-Hunt syndrome, whose illness lasted for 6 weeks with a complete recovery, except for the facial paralysis.

It is perhaps striking that herpes simplex is so lethal when it produces an encephalitis, and herpes zoster is not. To conclude, we must hope that further work on anti-viral agents and their relationship to these viruses will alter the invariably fatal prognosis of herpes simplex encephalitis.

\section{References}

Breeden, D.S., Hall, T.C. \& Tyler, H.R. (1966) Herpes simplex encephalitis treated with systemic 5-iodo-2 ${ }^{1}$ deoxyuridine. Ann. intern. Med. 65, 1050.

Evans, A.D., Gray, O.P., Miller, M.H., Verrier-Jones, E.R., WeEKs, R.D. \& Wells, C.E.G. (1967) Herpes simplex encephalitis treated with intravenous idoxuridine. Brit. med. J. 2, 407.

Heathfield, K.W.G., Pilsworth, R., Wall, B.J. \& CorSELlis, J.A.N. (1967) Coxsackie B5 infections in Essex 1965 , with particular reference to the nervous system. Quart. J. Med. 36, 579.

MacCallum, F.O., PotTer, J.M. \& Edwards, D.H. (1964) Early diagnosis of herpes-simplex encephalitis in brain biopsy. Lancet, ii, 332.

MARShall, W.J.S. (1967) Herpes simplex encephalitis treated with idoxuridine and external decompression. Lancet, ii, 579.

Miller, J.D. \& Ross, C.A.C. (1968) Encephalitis-a fouryear survey. Lancet, i, 1121.

Miller, J.K., Hesser, F. \& Tompkins, V.N. (1966) Herpes simplex encephalitis: report of 20 cases. Ann. intern. Med. 64, 92.

Rawls, W.E., Dycks, P.S. Klass, D.W., Green, H.D. \& HerRmanN, E.C. (1966) Encephalitis associated with herpes simplex virus. Ann. intern. Med. 64, 104.

Smith, M.G., Lennette, E.H. \& Reames, H.R. (1941) Isolation of the virus of herpes simplex and the demonstration of intranuclear inclusions in a case of acute encephalitis. Amer. J. Path. 17, 55. 